\begin{tabular}{|c|c|c|}
\hline PKS & REVISTA DE GEOGRAFIA & OJS \\
\hline $\begin{array}{l}\text { PUBLIC } \\
\text { KNOWLEDGE } \\
\text { PROJECT }\end{array}$ & $\begin{array}{c}\text { (RECIFE) } \\
\text { http://www.revista.ufpe.br/revistageografia }\end{array}$ & $\begin{array}{l}\text { OPEN } \\
\text { JOURNAL } \\
\text { SYSTEMS }\end{array}$ \\
\hline
\end{tabular}

\title{
A GEOGRAFIA DO MAL: UM ARQUIVO À SOMBRA DO DENUNCISMO
}

\author{
Bruno Nunes Batistal ${ }^{1}$ Antonio Carlos Castrogiovann ${ }^{2}$ \\ ${ }^{1}$ Doutor, Mestre e licenciado em Geografia pela Universidade Federal do Rio Grande do Sul. \\ Professor de Ensino Básico, Técnico e Tecnológico no Instituto Federal Catarinense. E-mail: \\ brunonunes.86@hotmail.com \\ ${ }^{2}$ Doutor em Comunicação Social (PUCRS). Mestre em Educação (UFRGS). Licenciado em \\ Geografia (UFRGS). Professor da Faculdade de Educação da UFRGS. E-mail: \\ castroge@ig.com.br
}

Artigo recebido em 26/06/2017 e aceito em 16/03/2018.

\begin{abstract}
RESUMO
Este artigo discute um dos elementos mais presentes nos textos pedagógicos da Geografia: a queda. Procura enfatizar que o denuncismo subjacente à Geografia que se faz na escola não é recente. Nesse sentido, certos arquivos, presentes no periódico Boletim Geográfico (1943-1978) permitem identificar algumas das raízes para entender por que, ainda hoje, escreve-se com determinadas normas, e com um dado jeito. O texto divide-se da seguinte maneira: primeiro, comenta sobre a análise de discurso à luz da arqueologia do saber de Michel Foucault. Na sequência, a partir do conceito de arquivo, compartilha fragmentos de textos sobre ensino de Geografia publicados entre a primeira e o início da segunda metade do século XX que descrevem o estado dessa disciplina escolar - e o resultado beira a catástrofe. Por último, insere tais ditames no interior da Modernidade, um período epistêmico que ajuda a pensar contemporaneamente as práticas pedagógicas. No meio disso tudo, uma singular constatação: a extinção da Geografia na Escola Básica.
\end{abstract}

Palavras-chave: Ensino de Geografia. Discurso. Estudos foucaultianos. Ordem do discurso geoescolar.

\section{GEOGRAPHY OF EVIL: A DENOUNCEMENT FILE}

\begin{abstract}
This article discusses one of the most present elements in the pedagogical texts of Geography: the fall. It tries to emphasize that the denunciation underlying Geography that is made in the school is not recent. In this sense, certain archives, present in the periodical Geographical Bulletin (1943-1978) allow us to identify some of the roots to understand why, even today, it is written with certain norms, and with a given way. The text is divided as follows: first, it comments on discourse analysis in the light of Michel Foucault's archeology of knowledge. Following on from the archive concept, it shares fragments of Geography teaching texts published between the first and the beginning of the second half of the twentieth century that describe the state of this school subject and the result is catastrophic. Finally, it inserts such dictates within modernity, an epistemic period that helps to think abaut the present pedagogical practices. In the middle of all this, a singular realization: the extinction of Geography in the Basic School.
\end{abstract}

Keywords: Teaching Geography. Speech. Foucauldian Studies. Order of geoschool speech. 


\section{PENSAR DIFERENTEMENTE O ENSINO DA GEOGRAFIA}

Para aqueles que se propõem a pesquisar acerca da Geografia escolar, comumente são apresentadas convenções, tratados, ou receituários por meio dos quais as suas respectivas trajetórias investigativas possam ser percorridas sem sobressaltos. Isso não é nem bom e nem ruim, e nem seria o caso de, aqui, desqualificar ou combater o que vem sendo robustamente produzido nessa subárea subjacente à escola. A minha intenção, na verdade, é outra: partilhar uma grade inteligibilidade, nem sempre realizada, porém profícua, na educação: a análise de discurso sob a ótica de Michel Foucault. Trata-se de uma maneira contrastante ao que comumente se executa nas linhas de pesquisa desse campo do conhecimento. Explico o porquê; faço-o resumindo o que, em linhas gerais, bastante se faz.

Muitas vezes, no ensino de Geografia, acontece a utilização de um método que possa levar à busca positiva das suas relações, procurando apontar como de fato o aluno aprende e/ou o professor ensina. Em outras, temos a dialética, segundo a qual as contradições presentes nas teorias e práticas pedagógicas poderiam serem amarradas por uma síntese. Encontramos, de forma semelhante, o materialismo dialético, encaminhando-nos para o encontro da verdade histórica, a luta de classes configurada pela opressão burguesa que poderia ser desvelada nas ações ocultas da Geografia escolar; ou quem sabe iluminar por meio dela a falsa consciência transmitida pelo aparelho ideológico da educação; ou, finalmente, situar o ensino de Geografia como instrumento de luta em prol de uma sociedade socialista, justa e igualitária. E também não poderíamos deixar de lado uma abordagem como a da fenomenologia, cujo objetivo seria o encontrar o sentido último que poderiam fazer dos estudos geográficos alavancas significativas para a construção do conhecimento com sentido para o estudante.

Parece-me que, entretanto, em não raros momentos esses universais métodos vêm se portando à semelhança de ferrolhos, "[...] que nos habituaram às corridas de cancha reta, onde tanto o ponto de partida, quanto o percurso, e mesmo o ponto de chegada são, tediosamente, visíveis" (CORAZZA, 2002, p. 109). Isso porque, ao fim e ao cabo, tais escolas atracar-seiam ora nos portos da razão positivista, através da qual aguçaríamos o olhar com que captamos o mundo; ora sob o alicerce do pensamento crítico, que assim nos possibilitaria revelar o invisível nas relações sociais. Em resumo, “[...] a razão científica ou filtraria ou espelharia corretamente o que é, na verdade, o mundo" (VEIGA-NETO, 2002, p. 27). 
Ao contrário dessas atitudes anteriores, nos últimos anos ando tentando transitar por um outro caminho: pensar o ensino da Geografia como uma formação discursiva (BATISTA, 2017a, 2017b). Levantar essa premissa significa tomá-lo enquanto um substrato feito de regras que estabelecem ditos e escritos a serem transmitidos, como se deve pronunciá-los - e quem pode fazê-los. Trata-se, nesse sentido, de um discurso constituído como “[...] elemento central das relações de poder inscritas na prática cotidiana da sala de aula e do currículo, reforçando hierarquias sociais e reproduzindo relações de saber e autoridade" (SILVA, 2013, p. 198).

Com as ferramentas foucaltianas em mãos, não procurei encontrar o oculto naquilo que é escrito, nem fazer o esforço de explicitar o que alguns autores do ensino de Geografia queriam mesmo dizer. Também, próximo que seria à hermenêutica, não busquei interpretar a profundidade das camadas que fariam do discurso uma matéria a ser elucubrada. Antes pelo contrário, um dos objetivos da corrente pesquisa foi apenas ater-se ao que estava sendo pronunciado nessa área do pensamento geográfico, descrevendo a regularidade de uma opinião, a manutenção fantasmagórica de uma teoria e a presença constante de um conjunto de ideias. Ao resultado discursivo do que foi feito dei o nome de ordem do discurso geoescolar (BATISTA, 2017), conceito que se refere à rede de objetos, enunciados e estratégias que vem fazendo do ensino da Geografia uma prática linguística estável que, da primeira metade do século XX em diante, comportou-se de um modo mais ou menos previsível.

Nesse artigo, irei debruçar-me sobre um dos elementos mais presentes nos textos pedagógicos da Geografia: a queda. Trata-se de uma característica que sinaliza o final do ensino de Geografia, a ameaça constante da sua extinção capitaneada, na maior parte dos momentos, pelas mãos dos seus próprios professores, que insistem em repetir uma Pedagogia arcaica, que não se concatena às exigências contemporâneas da sociedade brasileira. $\mathrm{O}$ que procurarei colocar em relevo é que, sem marcadores temporais ou uma data inaugural, o denuncismo subjacente à Geografia que se faz na escola não é nada recente e que certos arquivos nos permitem identificar algumas das raízes sistematizadas para entender por que, ainda hoje, escrevemos e dizemos sob a égide de determinadas normas, e com um dado jeito.

Nas próximas seções, o texto estará seccionado da seguinte maneira: primeiro, discutirei as teorizações sobre discurso com as quais opero, à luz da arqueologia do saber desenvolvida por Michel Foucault. Na sequência, a partir do conceito de arquivo, compartilho fragmentos de textos sobre ensino de Geografia publicados entre a primeira e o início da 
segunda metade do século XX que descrevem como ia indo essa disciplina escolar. Por último, ancoro tais preconizações no interior da Modernidade, um período epistêmico que nos ajuda a pensar contemporaneamente nossas práticas pedagógicas. Parece que é desse trampolim que algumas coisas começam a ficar interessantes de serem problematizadas.

\section{A ARQUEOLOGIA DE UM DISCURSO}

Ao perguntar como os discursos funcionam, Michel Foucault desenvolveu ao longo das suas pesquisas - e sistematizando mais precisamente em A arqueologia do saber - o método arqueológico. O que esse autor buscou fazer é, ao partir da análise de um dado discurso, organizar as suas regras de formação, o que ele aceita e o que ele nega; assim, descrever em termos conceituais “[...] a formação dos saberes, sejam eles científicos ou não, para estabelecer suas condições de existência, e não de validade, considerando a verdade como uma produção histórica" (MACHADO, 2006, p. 166). A verdade é uma produção histórica, cuja ressonância se dá através da elaboração de práticas linguísticas que distribuem relações de poder e normas de escrita.

Para a Geografia escolar isso pode ser enriquecedor, pois significaria não a ver como substrato de uma ordem cronológica, mas como concatenada a condições históricas que nos possibilitariam compreender "[...] o que se repete, o que instaura rupturas, o que se transforma, o que está nas fronteiras de um determinado tempo" (FISCHER, 2001, p. 220). Portanto, uma reflexão sistemática que não está almeja encontrar verdades absolutas para o trabalho pedagógico na ordem da Geografia, nem em, de maneira panfletária, colocar-se a favor ou contra ela. Com a arqueologia, o movimento está ligado a transformar o ensino da Geografia em um conjunto de documentos e, a partir daí, vê-los pela sua exterioridade. Distanciada das grandes categorias desencadeadas pelo Iluminismo, como o sujeito, a razão, o progresso ou a totalidade, essa abordagem apanha a contingência concatenada ao priori histórico e procura entender como isso se propagou em termos linguísticos. Por conseguinte, a arqueologia não seria um método, mas sim uma máquina (FOUCAULT, 2002), uma atividade (FISCHER, 2001), ou uma teorização (VEIGA-NETO, 1995), já que objetiva “[...] escavar verticalmente as camadas descontínuas do passado a fim de trazer à luz fragmentos de ideias, conceitos, discursos já esquecidos e aparentemente desprezíveis" (VEIGA-NETO, 1995, p. 21). Prática, no entanto, singela, porque não se coloca como fomentadora de uma liberdade abstrata, catalisadora de alguma revolução ou, muito menos, construtora de um 
paraíso utópico. Ao contrário, a proposta foucaultiana pergunta como um discurso funciona, como ele apareceu e foi se transformando naquilo que é.

A primazia, com efeito, é dada aos sistemas de linguagem, pois são eles que determinam o que é considerado verdade. Se falamos e pensamos sobre ensino de Geografia de um determinado jeito, isso se desenrolou pelos discursos hegemônicos que nos foram disponibilizados. Assim, somos limitados pela linguagem subjacente, imposta exteriormente, cabendo-nos apenas reprisá-la a partir de uma formação discursiva (FOUCAULT, 2008). As palavras empregadas passam a ter que respeitar regras de uso, estruturando-se formalmente através de desencadeamentos que as unem e conjuntos que as caracterizam; são elementos coordenados através de condições de coexistência, manutenção e modificação, que submetem objetos, conceitos e escolhas àquela dada repartição do discurso. Como resultado, é necessária a permissão para se referir a um dado discurso; Foucault (1996, p. 9) dizia que “[...] não se tem o direito de dizer tudo, que não se pode falar de tudo em qualquer circunstância, que qualquer um, enfim, não pode falar de qualquer coisa".

Ao pensarmos o ensino de Geografia como uma formação discursiva, teríamos que, sob a perspectiva da arqueologia foucaultiana, partirmos do pressuposto de que, nos seus sistemas de linguagem, leis são capitaneadas e coações exercidas, por intermédio de limites e fronteiras que controlam a disseminação dos discursos. Trata-se de um estado de policiamento linguístico, reconhecendo certas proposições como verdadeiras e outas como falsas. De fato, uma prática de interdição.

Panoramicamente, coloquei aqui algumas das ferramentas quando trabalhamos na perspectiva de discurso foucaultiana. Na sequência, veremos como a operacionalizei, colocando a Geografia da escola na centralidade dessa análise.

\section{DE ARQUIVO MORTO A MONUMENTO DE PESQUISA: O BOLETIM GEOGRÁFICO E AS CONTRIBUIÇÕES AO ENSINO}

De início, uma constatação identificável foi a de que o ensino de Geografia seria instituído à maneira de uma formação discursiva sólida, cuja amplitude seria derivada de uma longa faixa temporal: uma pesquisa em publicações em meados dos anos 1920 a 1930 demonstrou que refletir acerca de possibilidades no ensino dessa disciplina não é, de modo algum, atividade recente (BATISTA, 2017b). 
Foi na alavanca desse quadro que passei a compreender o considerável número de textos sobre a Geografia escolar enquanto um arquivo. Conceito central na fase arqueológica foucaultiana, trata-se de um conjunto total dos discursos que foram pronunciados ao longo de uma determinada época e que continuam presentes contemporaneamente, transformando enunciados e exortando que a formação de novas teorias se alinhe a "[...] regras de formação, de existência, de coexistência, a sistemas de funcionamento" (FOUCAULT, 2000, p. 146). O arquivo comporta um sistema que estabelece as leis do que pode ser dito, visto e escrito pelas pessoas em certos momentos e em certos lugares; desse modo, o arquivo evidencia que os textos podem ser condicionados a um jogo de regras, visto que efetuam o "[...] corte que nos separa do que não podemos mais dizer e do que fica fora de nossa prática discursiva" (FOUCAULT, 2008, p. 148).

A meu ver, o ensino de Geografia que se faz na contemporaneidade é o corolário de um antigo, porém ainda estável, arquivo. Essa é uma afirmação que faço a partir dos levantamentos analíticos em torno do Boletim Geográfico, publicação do Instituto Brasileiro de Geografia e Estatística (IBGE), que circulou nos espaços acadêmicos e técnicos entre o ano de 1943 (data da sua primeira edição) até 1978, quando foi extinto e posteriormente absorvido pela Revista Brasileira de Geografia. Sua periodicidade foi mensal até dezembro de 1951; em janeiro de 1952 torna-se bimestral, situação que permanece até dezembro de 1974; de janeiro de 1975 a julho de 1978, a publicação atinge temporalidade trimestral. Este periódico começou a ser planejado em 1941, na Assembleia Geral do Conselho Nacional de Geografia (instituição anterior ao IBGE), como um veículo que transmitisse informações geográficas e acadêmicas em formato de boletim. Ele é lançado, no entanto, apenas em abril de 1943, devido ao envolvimento do Brasil na Segunda Guerra Mundial, processo que atrasa sua produção. Na sua edição inaugura é denominado como Boletim do Conselho Nacional de Geografia, alcunha que permanece até a edição número 3, de junho de 1943.

Desde aquele momento, atinge uma tiragem média de 10 mil exemplares por edição, com preço acessível, constituindo, até 1978, a expressiva marca de 35 anos de editoração transmitidas em 259 publicações (PRÉVE, 1989). Era essa revista amplamente distribuída em território nacional pelas agências e delegacias do Instituto Brasileiro de Geografia e Estatística.

Um ponto que me fez colocar em relevo esse periódico em meio a outros tantos do período é a importância - até então inédita - que foi dada ao ensino da Geografia nas suas páginas. Isso porque o Boletim Geográfico, de 1943 a 1970, trazia seções específicas 
destinadas à educação, batizadas de "Contribuição didática (1943)", "Contribuição ao ensino (1944-1951)", “Contribuição à didática de Geografia (1952-1953)" e "Contribuição ao ensino (1953-1970). Totalizaram esses textos o surpreendente número de 497 trabalhos ancorados em teorias educacionais ou compartilhamento de metodologias de ensino.

Escrito por professores universitários ou de grandes colégios, tinha o Boletim Geográfico como destino profissionais e professores da Geografia, características que o fizeram ascender como uma publicação diferenciada. No que se refere à reserva de páginas ao ensino, a inovação foi ainda maior, pois era o único a fazê-lo na maior parte do tempo em que esteve vigente, assim como foi o primeiro a inaugurar tal abordagem. Interessante também é a qualidade dos materiais apresentados, assim como o rigor técnico dos conteúdos descritos, o que na, na visão de Préve (1989), demonstrava tanto um respeito com o professor de Geografia da Escola Básica como uma preocupação em mantê-lo atualizado.

É importante sublinhar, nessa perspectiva, que o Boletim Geográfico foi um inegável veículo de novas ideias e metodologias de ensino. Destaco que eventos como a implementação do curso de graduação em Geografia na Universidade de São Paulo, a presença do Instituto Brasileiro de Geográfica e Estatística e a criação da Associação dos Geógrafos Brasileiros foram processos que desaguaram nos textos publicados a partir dos anos 1940 no periódico em questão. Produto de uma época na qual o ensino público se expandia no país e reformas curriculares estavam em movimento, o Boletim Geográfico parecia estar concatenado ao que de mais contemporâneo produzia-se nas práticas educacionais.

Essa longa estadia no tempo e no espaço do pensamento geográfico brasileiro nos direciona a três constatações: a primeira é a marca que o Instituto Brasileiro de Geografia e Estatística cravou na educação básica, algo perceptível quando aparece em lembrança o expressivo número de materiais editados, obras avulsas, eventos e cursos de férias ofertados para professores. A segunda averiguação se refere à presença cativa dos textos do Boletim Geográfico tanto nas bibliografias dos cursos de graduação em Geografia quanto nas dos livros didáticos produzidos durante a faixa de tempo na qual esteve circulando (PRÉVE, 1989). A terceira constatação é que se trata de um registro histórico ao nível tanto de uma trajetória do pensamento geográfico quanto como reflexo das políticas públicas e de planejamento realizadas pelo governo federal. Assim sendo, quando perde relevância em meado dos anos 1970, por causa tanto do alastramento de informações geográficas em publicações marketizadas como pela massificação do livro didático - cujo preço era mais 
barato e a linguagem menos árida -, sua existência já estava enraizada no pensamento pedagógico brasileiro.

O Boletim Geográfico contribuiu para estabelecer os conteúdos presentes no currículo, uma metodologia própria de ensino e um padrão idealizado de professor de Geografia; igualmente, produziu algumas das raízes da ordem do discurso geoescolar. Dentre elas, irei na seção seguinte descrever uma das pedras angulares nos textos escolares contemporâneos que encontra guarida nos quase centenários textos do célebre arquivo que estamos discutindo: a possível extinção da Geografia, ora pelas mãos das distanciadas licenciaturas, ora pela precária carreira, ora, principalmente, pela resistência do professor em praticar atividades pedagógicas modernas.

Com a descrição de alguns textos, convido o leitor a viajar no tempo para refletir se, afinal, os textos atuais e os textos antigos do ensino de Geografia não seriam meros retalhos de uma mesma peça.

\section{DAR A VOZ AOS QUE NOS DEIXARAM}

“Ou a Geografia muda radicalmente e mostra que pode contribuir para formar cidadãos ativos, ou ela vai acabar virando peça de museu". Cause a surpresa que causar, mas é interessante frisar que o alerta de Vesentini (2004, p. 220) já foi dado, em outras épocas, por outros autores - contudo, eis que a Geografia escolar continua aí. Vejamos.

O anúncio da catástrofe foi enunciado em direção semelhante por Monbeig (1955, p. 423), nos momentos iniciais da palestra de abertura de um evento no Instituto Brasileiro de Geografia e Estatística (IBGE): "Estou aqui, também, porque disseram que o ensino da Geografia está no momento seriamente ameaçado no Brasil. Dizem que pessoas de boas intenções pretendem diminuir o ensino da Geografia no curso secundário”.

Essas duas citações, em momentos históricos distintos, nos servem para sinalizar as três famílias argumentativas que, no Boletim Geográfico, podem ser plotadas como forças causadoras do calvário da Geografia escolar: de um lado, a precariedade das condições institucionais; por outro, a péssima formação docente realizada nos cursos de licenciatura; como resultado, a manutenção de uma prática pedagógica anacrônica e desconectada do que se pensava didaticamente no discurso didático brasileiro.

Da perspectiva dos escassos recursos financeiros que abasteciam a educação, a crítica de Weiss $(1961,1962)$ é contundente. Ainda que seus textos tenham o intuito de compartilhar 
experiências pedagógicas que construiu, esse autor o faz posicionando-se do lugar-comum do professor que "[...] luta com as dificuldades típicas do desaparelhamento da maioria dos nossos educandários" (1961, p. 238). No entanto, esse panorama, segundo Weiss (1962), pode ser superado por meio da motivação do professor que, ao operar no campo do idealismo e da habilidade científica, pode colher excelentes resultados. Essa colocação, no entanto, não é compactuada por Pinto (1964): ao discorrer sobre as dificuldades dos alunos em compreenderem os signos cartográficos, seu ponto de partida encaixa-se no desconhecimento do professor sobre a constituição de um mapa; causa que, porém, pode advir do seu “[...] excesso de trabalho" (PINTO, 1964, p. 114). Como solução a curto-prazo, a resposta melhor viria da "[...] limitação de uma quinzena de horas por semana do horário dos professores, e uma retribuição bastante elevada para garantir a renda indispensável à segurança material e atividade intelectual” (MOINBEIG, 1945, p. 163). Infelizmente, o que ao contrário se vê é, afirma Moreira (1970, p. 77), um círculo vicioso no qual “[...] baixos vencimentos são responsáveis pela existência de professores fracos; professores medíocres, por si, não podem reivindicar melhores condições pecuniárias, ou, pelo menos, não estarão em condições de fazê-lo".

Com esse pano de fundo, os progressos metodológicos engendrados pela ciência geográfica tornam-se pedagogicamente inócuos frente à rotina dos seus professores; esses "[...] frequentemente têm muitas horas de aula, porque precisam ensinar uma outra matéria ou ter outras profissões, porque seus ordenados são insuficientes" (MONBEIG, 1945, p. 163). Como consequência, limitam-se ao planejamento das suas aulas por meio dos manuais escolares destinados aos alunos, o que inviabiliza "[...] o ensino exato e vivo da Geografia" (MONBEIG, 1945, p. 170). Sobre esses livros didáticos, a leitura de Damasceno é severa: “[...] o mercado acha-se abarrotado de livros didáticos de geografia que, mal comparados, parecem almanaques, tal a quantidade de informações, retratos de edifícios públicos e pontes fluviais remetidas aos alunos, e nada de caráter formativo" (1965, p. 320).

O segundo foco argumentativo nas páginas do Boletim Geográfico se desloca, por outro prisma, na deficitária formação pedagógica proporcionada ao licenciando. É sob esses parâmetros que incide parte das explicações para o estado geográfico-escolar. Para Monbeig (1944), as falhas dos cursos superiores não são apenas internas, mas decorrentes do histórico escolar dos alunos, que carregam uma bagagem metodológica advinda dos tempos de escola básica: "Não tendo nunca aprendido a trabalhar com método, a pensar e a ler com espírito crítico, têm um atraso considerável a vencer e a boa vontade do jovem nem sempre é 
suficiente para preencher as falhas de formação da criança" (MONBEIG, 1944, p. 8). Como antídoto, deve-se ter uma atenção especial às disciplinas técnico-pedagógicas, fundamental finalidade das faculdades de ciências humanas, que "[...] está longe de ser exclusivamente a formação de pesquisadores profissionais, mas também a de professôres destinados ao ensino secundário" (MONBEIG, 1944, p. 7). Como esse postulado não acontece, mantém-se a permanência do "defeituoso ensino de Geografia", situação que não pode ser atribuída apenas aos professores, já que esses “[...] não receberam um ensino especial de Geografia: seria difícil os considerar responsáveis" (MONBEIG, 1945, p. 163). Aliás, já eram encontrados na primeira metade do século XX professores lecionando Geografia de forma improvisada, situação condenável por Monbeig: “[...] da mesma que não é possível se improvisar em dentista ou advogado, não é possível se improvisar em professor, mesmo que seja de Geografia" (1945, p. 170).

Quem planta ventos colhe tempestades, e daí é óbvio que das enfadonhas práticas emergeria o desinteresse discente; essa é uma constatação sentenciada por Weiss (1962) para explicar as "[...] atitudes negativas [do aluno] quando o obrigam a memorizar cabos, ilhas e cidades importantes que são o conteúdo de uma pseudo Geografia” (p. 298). A resposta à problemática situação evoca que o professor de Geografia ensine as relações que a sociedade imprime na paisagem, pressuposto que, contudo, depende da "[...] renovação constante do professor, seja em conteúdo ou métodos” (WEISS, 1962, p. 299). Para tanto, ele “[...] deve ter a curiosidade intelectual que se adquire pela pesquisa e deve ter recebido uma formação científica que lhe permita se manter à corrente do progresso da Geografia" (MONBEIG, 1945, p. 170).

E, no meio desse turbilhão, o que se acabou vendo foi a redução da carga horária de Geografia ofertada aos alunos da Escola Básica, induzindo ao esquecimento do valor formativo do ensino geográfico na juventude, "[...] época em que o futuro cidadão adquire hábitos praticamente definitivos" (PEDROSO, 1966, p. 598). Como combate a esse quadro, haveria de existir qualquer outro pressuposto que não envolvesse uma categórica resposta à pergunta de Monbeig: "Será necessário concluir que a solução dos defeitos presentes não depende tanto de melhoras técnicas localizadas quanto de uma reforma mais vasta e radical?" (1945, p. 171).

Por último - mas não menos importante - é o eixo que concerne à denúncia da prática pedagógica tida como tradicional. É nesse ponto de análise que se centraram a maior parte dos textos sobre educação do Boletim Geográfico; é a manutenção desse modelo didático que 
alavancaria um processo irreversível através do qual os estudos geográficos acabariam por serem extintos. É o caso da visão de Backheuser (1943, p. 5): a Geografia, não obstante seu caráter de ciência elegante e digna da alta cultura, havia adentrado na fagueira descritiva, através da qual seu solo epistemológico era estabelecido pelo uso de "compêndios abarrotados" de listas de nomes a ser decorados; esse pressuposto engendrou uma desmoralização externa que esvaziou seu "lado científico e sedutor". Para Carvalho (1944, p. 7-13), a tendência à prática mnemônica causou um atraso metodológico - ou mesmo um ato de vingança daqueles que penaram com o decorar em excesso e agora querem que outros sofram do mesmo mal. O produto da nomenclatura geográfica pode ser descrito no Brasil do seguinte jeito: "Aqui, quem não sabe nomenclatura não sabe geografia; o ideal seria provavelmente um tratado volumoso, incluindo a lista telefônica" (CARVALHO, 1944, p. 7).

Ficheux (1950) comentaria que o método tradicional é desconectado da realidade do aluno; a redução do ensino a memória é desalentadora, processo enfadonho, pois esvazia de sentido o ensino; no jogo fácil de pergunta e resposta, deixa-se de lado o potencial da Geografia em fazer do "auditório escolar" um ambiente agradável, pautado por uma perguntaproblema que suscitaria um enérgico debate coletivo (FICHEUX, 1950, p. 854). No trabalho em grupo, complementa Reeder (1950), o conteúdo deixa de existir apenas por si mesmo e funciona como um substrato da constante mudança operada no espaço geográfico. Tal característica, no entanto, está sendo obstaculizada pela centenária memorização que, ao tomar como ponto de partida a simplificadora descrição, esquece que "A informação de hoje pode ser o erro de amanhã. A tolice de se ensinar geografia como uma descrição do mundo atual parece óbvia, levando-se em conta que hão de ocorrer modificações antes mesmo que as crianças das escolas cresçam" (REEDER, 1950, p. 1111).

Denúncia semelhante é empreendida por Azevedo (1951): estuda-se Geografia, de forma descontextualizada da realidade; a compartimentação do estudo dos países para além do Brasil isola-os, como se fossem territórios que não estabelecessem relações com outras nações. Um equívoco, pois, como explica Azevedo (1950, p. 556), um país deve ser compreendido levando pela sua unidade relacional, a simbiose entre os aspectos políticos, culturais, econômicos e sociais que o constituem como Estado-nação. É interessante de se frisar que a abordagem de Azevedo está alinhada com a própria linha editorial do Boletim Geográfico (p. 108), tanto que, na edição 106, de 1952, um texto coletivamente assinado posiciona-se contrário ao que se fazia de modo hegemônico nas práticas cotidianas do professor de Geografia, ou seja, o uso exagerado da nomenclatura. Carvalho nos diria que a 
construção da avaliação é comprometida por tal didática: o aluno, acaba cuidando "[...] mais de memorizar do que de compreender, porque não sabe estudar" (CARVALHO, 1952a, p. 326); algo cuja culpa não é sua, mas de uma prova “[...] baseada exclusivamente em mnemotécnica, em que a memorização é tida por tão importante que qualquer consulta é considerada fraudulenta, não permite semelhante apuração e verificação" (CARVALHO, 1952b, p. 748).

Justamente por isso que Dolabela (1954) utiliza o amparo de Delgado de Carvalho para pedir o rompimento do ensino tradicional, que é "[...] verbal, formalístico, abstrato e genérico" (p. 298), em favor de aplicações palpáveis, por meio das quais o aluno aprendesse fazendo e vendo ao invés de lendo e falando. Do contrário, “[...] o ensino das Ciências Geográficas é letra morta, ensino inerte e árido (BOLÉU, 1956, 288). Afinal de contas, a Geografia deve estar submetida aos objetivos da escola secundária; portanto, “[...] não são os professores indivíduos encarregados de fazer de seus alunos outros tantos geógrafos. Os próprios professores não têm necessidade imprescindível de ser geógrafos" (FONSECA, 1955, p. 643).

Cabral (1958), nesse âmbito, denuncia um ensino do “[...] tipo 'cabos e baías', por meio das quais exige-se das crianças somente a memorização do nome de cidades e principais produtos, em qualquer país" (p. 120); refere-se a um método “[...] demasiado formal, passivo e didático, apelando só para a memória e não para a compreensão ou a imaginação infantil (p. 120). Santos (1959), a partir de observações realizadas em salas de aula, deparou-se com professores insistindo em enfatizar a memorização de acidentes geográficos, situação vista pelo autor com incredulidade: "É sabido que a Geografia atual não é mais a dos tempos medievais ou da Antiguidade, fases em que a sua principal característica era a de Geografia Descritiva” (SANTOS, 1959, p. 405).

Até aqui, claras constatações: pessimismo é regra, a eminente catástrofe paira sob o ensino da Geografia. Num extremo, tudo que era para ter sido e não foi. No outro, a representação de uma distópica realidade geográfica-escolar. No cotidiano escolar, o ensino de Geografia continuava se movendo. Em qual sentido, poucos poderiam dizer. Restaria, antes de encerramos, entender sob a égide de quais padrões morais esse denuncismo discursivamente lançava suas âncoras, pois é daí que entenderíamos porque ele ainda parece manter-se. 


\section{O LASTRO DA MODERNIDADE}

Parece que muitos dos discursos cujos fundamentos operacionalizamos até os dias atuais podem ter procedência num específico período europeu entre o final da Idade Média e os primórdios da Era Moderna. Um conjunto de mudanças através das quais o feudalismo foi deslocando-se para um sistema capitalista de troca e produção; uma série de inovações técnicas inventadas, como a imprensa e a codificação de informações; transformações políticas, implicando na formação de estados-nações regularmente centralizados e com uma configuração delimitada de administração e tributação; a construção das identidades nacionais, com a posterior emergência do uso legítimo da força pelo soberano, dentro de um determinado território (THOMPSON, 2013). Um perene espectro, catalisador de narrativas que, englobadas, aprendemos a categorizar como Modernidade. É tal pedra angular que, no meu entendimento, acompanha parte das organizações discursivas subjacentes à ordem do discurso geoescolar.

Pedirei auxílio aqui a dois pesquisadores nessa tarefa de identificar uma prevalência de ideias no que assinalamos como Modernidade.

O primeiro deles é Latour (1994): para ele, a Modernidade tem como premissa atracarse no porto da dicotomia entre um passado arcaico e um futuro evoluído; assim, é empreendida a noção de ruptura, que demarca o tempo através de uma série regular de datas, graças ao qual os acontecimentos são sendo imaginados sucessivamente do atraso ao progresso. Esse autor assinala a presença de uma flecha temporal irreversível, cuja direção escolhida pelo viés modernizador significa a saída de uma idade das trevas rumo à verdade científica do melhor dos mundos; nesse rumo, o que não o acompanha passa a ser reconhecido como irracional e/ou conservador. A lógica dual do estático e do dinâmico, do atraso e do progresso, da conservação e da evolução são linhas que nos acompanham ainda hoje, levando Latour (1994, p. 41) a afirmar que "Quem nunca sentiu vibrar dentro de si esta dupla potência, ou quem nunca foi obstinado pela distinção entre o racional e o irracional, entre falsos saberes e verdadeiras ciências, jamais foi moderno".

Já Mafessoli (2010) comenta sobre o universalismo idealizado por algumas das narrativas modernas, afirmando que através de expressões como o progresso, a igualdade e a humanidade, o que acabou se produzindo foi a) a história enquanto marcha única em direção ao finalismo perfeito e b) um discurso moralizante, irrigado por um contínuo dever-ser capitaneado pelas ladainhas rivalizantes entre o "[...] Bem e o Mal, o Verdadeiro e o Falso, o 
Justo e o Injusto, o Perfeito e o Imperfeito, a Civilização e a Barbárie” (MAFFESOLI, 2010, p. 49).

Com essas duas linhas de raciocínio, o que estou querendo dizer é que no bojo da ordem do discurso geoescolar preexiste uma veia da Modernidade alavancada por narrativasmestras, cujas órbitas se movimentam em torno da ruptura e da imposição. Trata-se de dois fundamentos que, tendo como um dos seus solos originários uma publicação do porte do Boletim Geográfico, fornecem-nos faróis para entender o que vem sendo pensado, escrito e dito sobre o ensino de Geografia. Bastaria que levássemos em conta, nesse contexto, a constante referência negativa em livros, artigos, dissertações e teses às práticas pedagógicas antigas e/ou tidas como tradicionais para termos em mãos guias de conduta de como deve ser a aula ideal no início do século XXI.

Nesse sentido, o discurso dessas propostas educacionais visa a substituição do passado por modelos didáticos adaptados ao tecido social do presente. É daí que vemos insurgir o enunciado saturado que nega o presente pedagógico, esmera-se por comprovar a sua insuficiência, e procura vertê-lo em prol de um novo eixo de desenvolvimento. Ora, é sem esforço que podemos identificar em grande parte dos textos sobre ensino de Geografia argumentos relacionados às novas competências do professor, o lastro que dá sustento às "boas práticas" e as prescrições pedagógicas estruturada em progressão, mediante "[...] a qual o avanço e a mudança são sempre elementos necessários" (GOMES, 1996, p. 49). Com efeito, o modo como se organiza discursivamente a Geografia escolar torna-a porosa à série de modismos que questionam o modelo pedagógico vigente a partir de alguma didática contemporânea; antes, no entanto, é necessário destruir, ultrapassar e romper com o passado, sinalizando novos tempos. Um dilema, aliás, eminentemente paradoxal, posto que com um pé na defenestração do passado e outro no idealismo do futuro, o que se é uma descaracterização do presente, julgado por sua suposta incompletude e vivido sob o mantra do dever-ser (BATISTA, 2017b).

Distribuído através dos regimes de verdade presentes em textos pedagógicos da primeira metade do século XX, e como parte de "[...] um refrão sem contestação de nenhuma ordem; um aspirante sequioso à absolutização histórica" (AQUINO, 2014, p. 153), o ensino da Geografia vem mostrando-se parcialmente incapaz de operar suas linhas de força sem que o faça edificando regras a partir dos escombros da Pedagogia tradicional, suprema inimiga do avanço dos sistemas de ensino. Ancorado nas pragas pedagógicas (VEIGA-NETO, 2012) do catastrofismo, do denuncismo e do reducionismo, os poucos que ainda adentram nesse campo 
profissional tornam-se endividados com práticas ruins que não fizeram e que, inevitavelmente, vão fazer. Por outro lado, escrever sobre Geografia e escola não raras vezes é sinônimo de trabalhar sobre uma terra arrasada, cujo inventário dos defeitos deve ser minucioso e classificado.

É preciso dizer que, no entanto, muitos já percorreram essas trilhas do criticismo, e bem antes de nós. Foi o que procurei aqui partilhar. Talvez nossas reflexões sobre a contemporaneidade geográfica-educacional possam utilizar de alguma forma esse pressuposto.

\section{PONTUAÇÕES FINAIS}

Não houve, neste breve texto, a sedução da teoria científica cuja promessa é a verdade, “[...] que apesar de não cumprida e muitas vezes desacreditada, renova-se sempre" (COSTA, 1995, p. 153); nem a vontade de comprovar argumentos com os quais se ratifique que a Geografia possua “[...] uma missão salvacionista ou que ela tenha, por si mesma, o papel de formar moralmente os indivíduos" (VEIGA-NETO, 2003, p. 105). Ao desencaixar-me do método alicerçada na dicotomia entre teoria e prática, entre um mundo inteligível e um mundo sensível, do qual o segundo é melhorado pelo primeiro (ou o primeiro não acompanha as características do segundo), o que tentei fazer foi descer ao nível apenas do que foi dito, indagando acerca de quem fala sobre ensino de Geografia, como se fala sobre ensino de Geografia, onde se fala sobre ensino de Geografia e de onde se fala sobre ensino de Geografia.

Fiz, então, um instrumento prático de leitura dos discursos da Geografia escolar em meados da primeira metade do século XX e um pouco mais além. Não se tratou, justamente por isso, de uma doutrina, nem a construção de uma nova teoria, mas apenas da análise de das algumas regras que ditam o ritmo dos ditos e escritos geopedagógicos.

Sem sustos, sem sobressaltos, sem notas dissonantes ou histórias inéditas. De 1943 a 1970, no Boletim Geográfico, a seção "Contribuição ao ensino" ajudou a mapear uma visão, em certo limite panorâmica, em alguns momentos bem localizada, das características e vivências subjacentes à Geografia. O cenário desenhado não poderia ser mais desanimador: um ensino desencaixado da efervescente Geografia edificada nas principais universidades; uma prática mnemônica que infernizava alguns alunos e desmotivava a maioria; a didática 
descritiva, cansativa, numérica, nominalista e desvinculada dos processos históricos, sociais e materiais que produziam o espaço geográfico brasileiro e mundial.

Falavam desse quadro e assinavam embaixo com invejável certeza professores com titulação acadêmica apropriada e louvável, e pertencentes, em sua maioria, à rede universitária; e alguns poucos pesquisadores da área da educação de países europeus que colaboravam de forma estreita com os cursos de Geografia das universidades brasileiras. Docentes esses que lecionavam disciplinas de didática, orientavam estagiários e acompanhavam de maneira aproximada as rotinas escolares - portanto, sujeitos que, no discurso ordenado, eram mais do que autorizados a poder falar sobre ensino de Geografia.

São eles que vão vir a formatar os elementos abstratos e subjetivos correspondentes à palavra-mestra a partir de então reconhecida como professor tradicional de Geografia aquele que fala exaustivamente, descreve paisagens petrificadas como um limitado guia turístico; que, ao final, manda os alunos memorizarem tudo que ouviram.

Esse - o professor tradicional - haverá de ser um dos grandes inimigos dos pesquisadores desse campo do conhecimento. Mas, é preciso que se frise, também será pedra angular para começar qualquer texto e fala referente à Geografia escolar. No extremo, daria para se afirmar que o campo de pesquisa do ensino de Geografia não vivia sem regurgitar a todo momento a figura do seu velho e maldito parceiro pedagógico. A questão é: vive, ainda?

\section{REFERÊNCIAS}

AQUINO, Julio Groppa. Da autoridade pedagógica à amizade intelectual: uma plataforma para o éthos docente. São Paulo: Cortez, 2014.

AZEVEDO, Aroldo de. Programa de Geografia para o Curso Secundário. Boletim Geográfico, Rio de Janeiro, v. 9, n. 101, ago. 1951.

BACKHEUSER, Everaldo. Tertúlias geográficas. Boletim do Conselho Nacional de Geografia, Rio de Janeiro, v. 1, n. 2, maio 1943.

BATISTA, Bruno Nunes. A ordem do discurso geoescolar. Tese (Doutorado em Geografia). Instituto de Geociências, UFRGS. Porto Alegre, 2017a.

Como nos tornamos professores de Geografia: discurso ordenado, prática neoliberal. Revista Pedagógica, Chapecó, v. 19, n. 42, p. 130-153, set.-dez. 2017 b.

BOLÉU, José de Oliveira. Técnicas do ensino das Ciências Geográficas. Boletim Geográfico, Rio de Janeiro, v. 14, n. 132, mai.-jun. 1956.

BOLETIM GEOGRÁFICO. Programa de Geografia e instrução metodológica para a sua execução. Boletim Geográfico, Rio de Janeiro, v. 10, n. 106, jan-fev. 1952. 
CABRAL, Eddy Flores. O ensino de Geografia. Boletim Geográfico, Rio de Janeiro, v. 16, n. 145, jul.-ago. 1958.

CARVALHO, Delgado de. O Ensino da Geografia no curso de Humanidades. Boletim Geográfico, Rio de Janeiro, v. 1, n. 10, jan. 1944.

Didática das Ciências Sociais. Boletim Geográfico, Rio de Janeiro, v. 10, n. 108, maio-jun. 1952a.

Didática das Ciências Sociais (continuação). Boletim Geográfico, Rio de Janeiro, v. 10, n. 111, nov.-dez. 1952b.

CORAZZA, Sandra Mara. Labirintos da pesquisa, diante dos ferrolhos. In: COSTA, Marisa Vorraber (Org.). Caminhos investigativos: novos olhares em educação. Rio de Janeiro: DP \& A, 2002.

COSTA, Marisa C. Vorraber. Elementos para uma crítica das metodologias participativas de pesquisa. In: VEIGA-NETO, Alfredo (Org.). Crítica pós-estruturalista e educação. Porto Alegre: Sulina, 1995.

DAMASCENO, Daury Fontenelle. Algumas considerações sobre o emprego do material didático no ensino da Geografia. Boletim Geográfico, Rio de Janeiro, v. 24, n. 185, mar.abri. 1965.

DOLABELA, Elzio. Geografia, ensino e pesquisa. Boletim Geográfico, Rio de Janeiro, v. 12, n. 122, set.-out. 1954.

FICHEUX, M. R. Ensino da Geografia II. Boletim Geográfico, Rio de Janeiro, v. 8, n. 86, mai. 1950.

FISCHER, Rosa Maria Bueno. Foucault e a análise do discurso em educação. Cadernos de Pesquisa da Fundação Carlos Chagas, São Paulo, v. 114, 2001.

FONSECA, James B. Viera da. O Ensino da Geografia. Boletim Geográfico, Rio de Janeiro, v. 13, n. 129, nov.-dez. 1955.

FOUCAULT, Michel. A ordem do discurso: aula inaugural no Collège de France pronunciada em 2 de dezembro de 1970. São Paulo: Edições Loyola, 1996.

Ditos e escritos II: Arqueologia das ciências e histórias dos sistemas de pensamento. Rio de Janeiro: Forense Universitária, 2000.

A verdade e as formas jurídicas. Rio de Janeiro: NAU Editora, 2002.

. A arqueologia do saber. Rio de Janeiro: Forense Universitária, 2008.

GOMES, Paulo Cesar da Costa. Geografia e modernidade. Rio de Janeiro: Bertrand Brasil, 1996.

LATOUR, Bruno. Jamais fomos modernos: ensaio de antropologia simétrica. Rio de Janeiro: Editora 34, 1994.

MACHADO, Roberto. Foucault, a ciência e o saber. Rio de Janeiro: Jorge Zahar, 2006.

MAFFESOLI, Michel. Saturação. São Paulo: Iluminuras, 2010.

MONBEIG, Pierre. Estudos Geográficos. Boletim Geográfico, Rio de Janeiro, v. 1, n. 11, fev. 1944. 
maio 1945.

A Geografia no ensino secundário. Boletim Geográfico, Rio de Janeiro, v. 3, n. 26,

A Geografia no Ensino Secundário. Boletim Geográfico, Rio de Janeiro, v. 13, n. 127, jul.-ago. 1955.

MOREIRA, Igor Antônio Gomes. A Geografia como ciência humana e de síntese e as implicações no ensino secundário. Boletim Geográfico, v. 29, n. 218, 1970.

PEDROSO, Tabajara. A Geografia no curso secundário. Boletim Geográfico, Rio de Janeiro, v. 25, n. 194, set.-out. 1966.

PINTO, Maria Magdalena Vieira. Orientação metodológica para uso do atlas geográfico escolar. Boletim Geográfico, Rio de Janeiro, v. 22, n. 178, jan.-fev. 1964.

PREVÉ, Orlandina da Silva Damian. A participação do Boletim Geográfico do IBGE na produção da metodologia do ensino da Geografia. Dissertação (Mestrado em Educação Metodologia de Ensino) - Faculdade de Educação, UNICAMP. Campinas, 1989.

REEDER, Edwin W. O espírito do ensino moderno da Geografia. Boletim Geográfico, Rio de Janeiro, v. 8, n. 93, dez. 1950.

SANTOS, Maurício Silva. O ensino da Geografia no curso secundário noturno. Boletim Geográfico, Rio de Janeiro, v. 17, n. 151, jul.-ago. 1959.

SILVA, Tomaz Tadeu da. Currículo e identidade social: Territórios contestados. In: Silva, Tomaz Tadeu da (Org.). Alienígenas na sala de aula: uma introdução aos estudos culturais em educação. Petrópolis, RJ: Vozes, 2013.

THOMPSON, John B. A mídia e a modernidade: uma teoria social da mídia. Petrópolis, RJ: Vozes, 2013.

VEIGA-NETO, Alfredo. Michel Foucault e educação: há algo de novo sob o sol? In: VEIGANETO, Alfredo (Org.). Crítica pós-estruturalista e educação. Porto Alegre: Sulina, 1995.

. Olhares... In: COSTA, Marisa Vorraber (Org.). Caminhos investigativos: novos olhares em educação. Rio de Janeiro: DP \& A, 2002.

Pensar a escola como instituição que pelo menos garanta a manutenção das conquistas fundamentais da modernidade. In: COSTA, Marisa Vorraber (Org.). A escola tem futuro? Rio de Janeiro: DP \& A, 2003. 2012.

. É preciso ir aos porões. Revista Brasileira de Educação, v. 17, n. 50, maio-ago.

VESENTINI, José William. Realidades e perspectivas do ensino de Geografia no Brasil. In: VESENTINI, José William (org.). O ensino de Geografia no século XXI. Campinas: Papirus, 2004.

WEISS, Arthur Bernardes. Didática da Geografia. Boletim Geográfico, Rio de Janeiro, v. 19, n. 161, mar.-abri. 1961.

O problema da motivação no ensino da Geografia. Boletim Geográfico, Rio de Janeiro, v. 20, n. 168, mai.-jun. 1962. 